\title{
Investigation Study of Pressure Different Effect at Evaporator in Organic Rankine Cycle Simulator (ORCS) Using Low-grade Waste Heat
}

\author{
Mochamad Denny Surindra ${ }^{1}$ Wahyu Caesarendra ${ }^{2, *}$
}

\author{
${ }^{1}$ Mechanical Engineering, Politeknik Negeri Semarang, Semarang 50275, Indonesia \\ ${ }^{2}$ Faculty of Integrated Technologies, Universiti Brunei Darussalam, Jalan Tungku Link, Gadong BE1410, Brunei \\ Darussalam \\ *Corresponding author. Email: wahyu.caesarendra@ubd.edu.bn
}

\begin{abstract}
Organic Rankine Cycle (ORC) was presented an efficient solution for low-grade waste heat exploitation, due to its uncomplicated mechanism, required less pressure, simple and compact components, and accessible maintenance. The evaporator has the characteristics of a pressure drop due to irreversibility which there was friction between working fluid and the heat exchanger channel walls. Working fluid are utilized for mixture-ratio between R123 and R245fa, and each individual refrigerant i.e. R123 and R245fa, all of them are changed in mass flow rate with verity of $0,1 \mathrm{~kg} / \mathrm{s}$ and $0,2 \mathrm{~kg} / \mathrm{s}$. Difference of boiling point, freezing point, critical temperature and critical pressure could be identified by Ts diagram due to different molecular weight with the lowest of R245fa and the highest of R123. Pump performance produces volume rate and shows pressure different at evaporator with the highest $\Delta$ Pevap of 0.95 bar, when utilized working fluid of R123. When an expansion process in the expander, molecule weight provides a more massive motion energy intake, therefore working fluid R123 has the highest expander power output and the greatest thermal efficiency
\end{abstract}

Keywords: Low Grade Waste Heat, Evaporato, Organic Ranckine Cycle Simulator

\section{INTRODUCTION}

Electrical energy demand leads to increased consumption of fossil fuels and a massive release of pollutants, leading to the development of low-grade heat utilization. In Indonesia, there was a huge amount of low-grade waste heat in industrial activities. Waste heat recovery has been perform potentially on many occasions. However, the amount of recovery is insufficient. There is still abundant waste heat which has not been fully utilized [1,2]. Organic Rankine Cycle (ORC) was presented to be an efficient solution for lowgrade waste heat exploitation, due to its uncomplicated mechanism, required less pressure, simple and compact components, and accessible maintenance [3].

Extensive investigations have been carried out, consisting the selecting of working fluid, design and optimization system. R245fa working fluid is usually chosen as a working fluid in the organic Rankine cycle (ORC) and high temperature heat pump systems because of its high critical temperature at $154{ }^{\circ} \mathrm{C}$, which is useful for use in ORC application and high temperature heat pumps [4]. Guo et al. [5], and Galloni et al. [6] utilized R245fa as the circulating agent for the ORC system in their experimental research work, whose results show that $\mathrm{R} 245 \mathrm{fa}$ working fluid can be safety guaranteed in the system operation process. On the other hand, through research has just been published, Prasetyo et al. [7] and Sarmiento [8] revealed R123 working fluid has been adopted to produce the highest ORC efficiency and environmental performance. Furthermore, in order to find alternative working fluid which appropriate with design challenge and complicated application, Surindra et al.,2019 [9] established ORCS as simulator of Organic Rankine Cycle test bench with mixed-ratio of working fluid R123, and R245fa.

Many researchers have disclosed the ORC system, but insufficient number of presenting have studied the evaporator. Indeed there are those who are interested like Kong et al. [10] has already reported his comprehensive study that the external irreversibility during heat transfer at evaporator. They used different temperature as heat source at $80^{\circ} \mathrm{C}-110^{\circ} \mathrm{C}$. In this paper 
focused on the difference of pressure in the evaporator. As we know Plate Heat Exchanger (PHE) has the characteristics of a pressure drop due to irreversibility which there was friction between working fluid and the heat exchanger channel walls but so far there has been no comprehensive report explaining the effect of this pressure drop. The changes in mass flow rate would be varied, and its effect on the pressure difference in the evaporator would be explored, especially impact to expander power output and ORC system.

\section{METHODOLOGY: GENERAL EXPERIMENTAL CONDITIONS}

Within this research, working fluid are utilized for mixture-ratio between R123 and R245fa, and each individual refrigerant i.e. R123 and R245fa, all of them are changed in mass flow rate with verity of $0,1 \mathrm{~kg} / \mathrm{s}$ and $0,2 \mathrm{~kg} / \mathrm{s}$, then investigated how high power output of expander and efficiency system.

\subsection{Heating cycle}

The simulated heat source uses $40 \mathrm{~kW}$ of capacity to heat the oil in the tube until it reaches a temperature of $120{ }^{\circ} \mathrm{C}$ in the inlet evaporator. Hot oil circulation uses an adjustable axial pump to convert the mass flow rate to the evaporator. During the experiment using axial pumps that have formed at a speed of $55 \mathrm{~Hz}$, therefore, it is likely that the heat flow conditions that flow into the evaporator are uniform without any change. The lubricating oil used from the TOTAL company with SERIOLA K 3120 type has a specific heat (cp) of $0.5353 \mathrm{kcal} / \mathrm{kg}{ }^{0} \mathrm{C}$, so the amount of mass flow rate of hot oil in table 1 as follows.

Table 1. The mass flow rate of hot oil

\begin{tabular}{ccccc}
\hline R245fa & R123 & R245fa 2:1 R123 & R245fa 1:1 R123 & R245fa 1:2 R123 \\
\hline $\mathrm{kg} / \mathrm{s}$ & $\mathrm{kg} / \mathrm{s}$ & $\mathrm{kg} / \mathrm{s}$ & $\mathrm{kg} / \mathrm{s}$ & $\mathrm{kg} / \mathrm{s}$ \\
3.51 & 7.55 & 3.52 & 3.23 & 3.66 \\
3.45 & 8.27 & 3.72 & 3.68 & 3.74 \\
3.51 & 9.39 & 3.65 & 3.48 & 3.97 \\
3.60 & 10.05 & 3.89 & 4.05 & 4.37 \\
3.95 & 10.30 & 4.28 & 4.55 & 4.81 \\
\hline
\end{tabular}

\subsection{Working fluid cycle}

Efforts to obtain a working fluid according to the ORC system were carried out by mixing pure refrigerant R123 and R245fa. Surindra et al. [9] have reported that they mix R123 and R245fa to operate the ORC system. R245fa 1:1 R123 (admixture R123 50\% and 50\% R245fa), R123 2:1 R245fa (admixture R123 $66,6 \%$ and $33,3 \% \mathrm{R} 245 \mathrm{fa})$ and R245fa 1:2 R123 (admixture R245fa 33,3\% and 66,6\% R123). Determine the working fluid cycles in the system with mass flow rate at $0,1 \mathrm{~kg} / \mathrm{s} ; 0,13 \mathrm{~kg} / \mathrm{s} ; 0,15 \mathrm{~kg} / \mathrm{s} ; 0,18$ $\mathrm{kg} / \mathrm{s}$ and $0,2 \mathrm{~kg} / \mathrm{s}$.

\subsection{Cooling cycle}

Cooling utilizes water from cooling towers with mass flow rates ranging from $2,12 \mathrm{~kg} / \mathrm{s}$ to $3,00 \mathrm{~kg} / \mathrm{s}$, based on data in table 2 , it is satisfied that the mass flow rate of cooling water flowing into the condenser is uniform for all experimental processes as for to change the mass flow rate by turning the needle valve. Temperature air cooling tower fluctuates due to the influence of the environment. A cooling tower is located on the roof of a manufacturing factory building to serve the cooling system. 
Table 2. Data condition of cooling cycle operation

\begin{tabular}{|c|c|c|c|c|c|c|c|c|c|c|c|c|c|c|}
\hline \multirow[b]{2}{*}{$\begin{array}{l}\text { Cold } \\
\text { water } \\
\text { inlet }\end{array}$} & \multicolumn{3}{|c|}{$\mathrm{R} 245 \mathrm{fa}$} & \multicolumn{2}{|l|}{$\mathrm{R} 123$} & \multicolumn{3}{|c|}{$1 \mathrm{R} 245 \mathrm{fa}: 1 \mathrm{R} 123$} & \multicolumn{3}{|c|}{2 R245fa: 1 R123 } & \multicolumn{3}{|c|}{ 1 R245fa : 2 R123 } \\
\hline & $\begin{array}{l}\text { Cold } \\
\text { water } \\
\text { outlet }\end{array}$ & $\begin{array}{l}\text { Flow } \\
\text { Rate }\end{array}$ & $\begin{array}{l}\text { Cold } \\
\text { water } \\
\text { inlet }\end{array}$ & $\begin{array}{l}\text { Cold } \\
\text { water } \\
\text { outlet }\end{array}$ & $\begin{array}{l}\text { Flow } \\
\text { Rate }\end{array}$ & $\begin{array}{l}\text { Cold } \\
\text { water } \\
\text { inlet }\end{array}$ & $\begin{array}{l}\text { Cold } \\
\text { water } \\
\text { outlet }\end{array}$ & $\begin{array}{l}\text { Flow } \\
\text { Rate }\end{array}$ & $\begin{array}{l}\text { Cold } \\
\text { water } \\
\text { inlet }\end{array}$ & $\begin{array}{l}\text { Cold } \\
\text { water } \\
\text { outlet }\end{array}$ & $\begin{array}{l}\text { Flow } \\
\text { Rate }\end{array}$ & $\begin{array}{l}\text { Cold } \\
\text { water } \\
\text { inlet }\end{array}$ & $\begin{array}{l}\text { Cold } \\
\text { water } \\
\text { outlet }\end{array}$ & $\begin{array}{l}\text { Flow } \\
\text { Rate }\end{array}$ \\
\hline${ }^{0} \mathrm{C}$ & ${ }^{0} \mathrm{C}$ & $\mathrm{Kg} / \mathrm{s}$ & ${ }^{0} \mathrm{C}$ & ${ }^{\circ} \mathrm{C}$ & $\mathrm{Kg} / \mathrm{s}$ & ${ }^{0} \mathrm{C}$ & ${ }^{0} \mathrm{C}$ & $\mathrm{Kg} / \mathrm{s}$ & ${ }^{0} \mathrm{C}$ & ${ }^{0} \mathrm{C}$ & $\mathrm{Kg} / \mathrm{s}$ & ${ }^{0} \mathrm{C}$ & ${ }^{0} \mathrm{C}$ & $\mathrm{Kg} / \mathrm{s}$ \\
\hline 27.67 & 30.55 & 2.14 & 25.65 & 27.96 & 2.12 & 30.21 & 30.25 & 2.48 & 19.28 & 21.61 & 2.43 & 25.04 & 27.04 & 2.61 \\
\hline 28.46 & 32.04 & 2.12 & 16.27 & 18.27 & 3.17 & 28.50 & 31.20 & 2.44 & 19.96 & 22.82 & 2.46 & 25.35 & 27.89 & 2.55 \\
\hline 28.85 & 33.01 & 2.13 & 16.25 & 18.54 & 3.12 & 28.29 & 31.02 & 2.74 & 21.50 & 24.78 & 2.47 & 25.63 & 28.45 & 2.61 \\
\hline 29.06 & 33.52 & 2.15 & 16.33 & 18.70 & 3.04 & 28.31 & 31.15 & 2.83 & 21.57 & 25.03 & 2.58 & 25.66 & 28.60 & 2.74 \\
\hline 29.11 & 33.70 & 2.20 & 18.42 & 20.97 & 3.00 & 28.37 & 31.35 & 2.99 & 21.09 & 24.66 & 2.71 & 25.66 & 28.63 & 3.03 \\
\hline
\end{tabular}

\section{RESULTS AND DISCUSSION}

\subsection{Different pressure effects on the evaporator}

Rankine cycle in figure 1 reveals about the irreversibility and losses associated with each of the

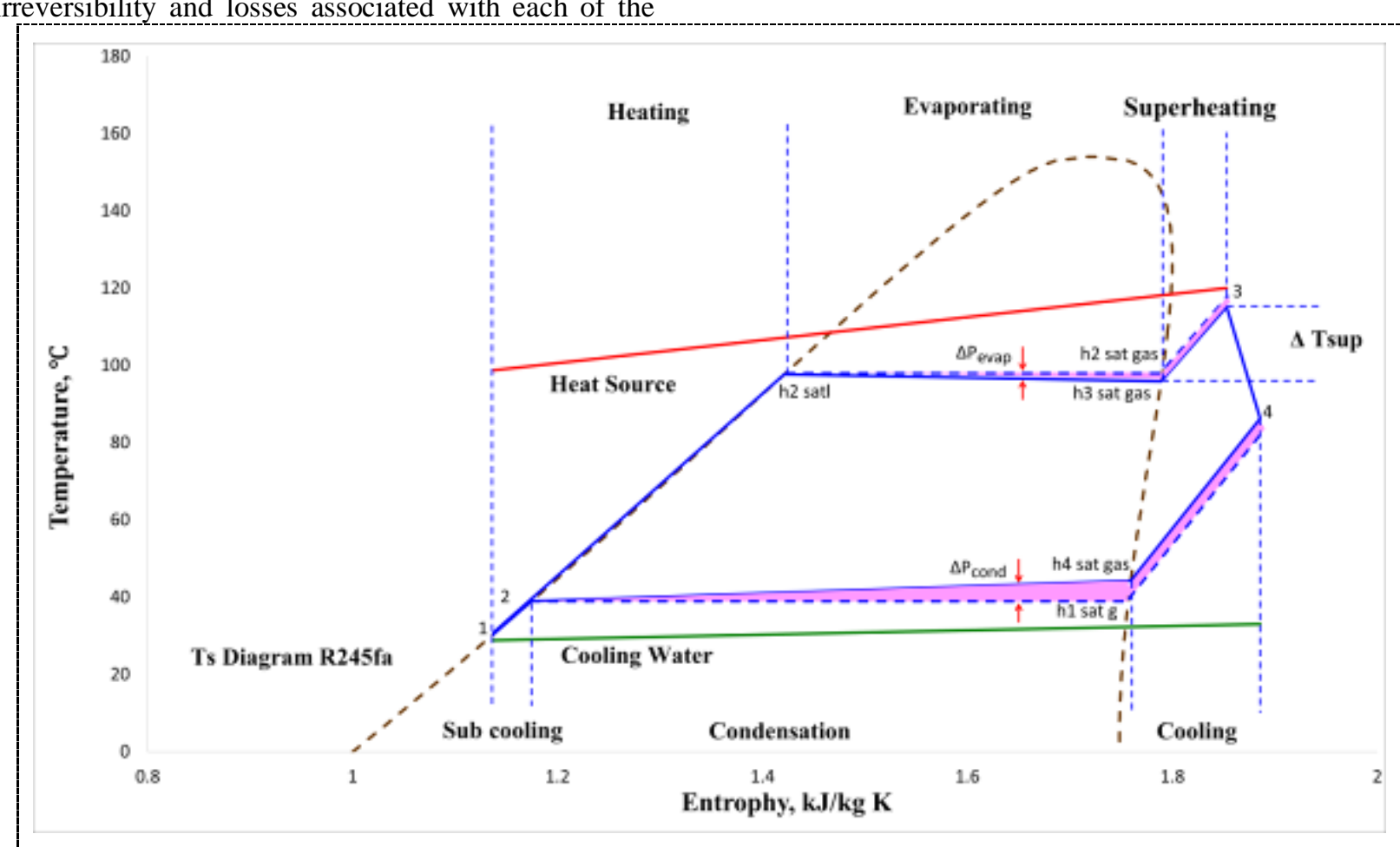

Figure 1. Rankine cycle with pressure difference due to irreversibility at evaporator and condenser

Rankine cycle presents a process of power cycle vapor that flows through several main components, i.e., pump, evaporator, expander, and condenser. Working fluids flowing within the sequence will experience four subsystems experienced by the working fluid as it is circulated through a closed circuit of the Rankine cycle. 
actual and ideal difference of the Rankine cycle is of concern to be discussed further.

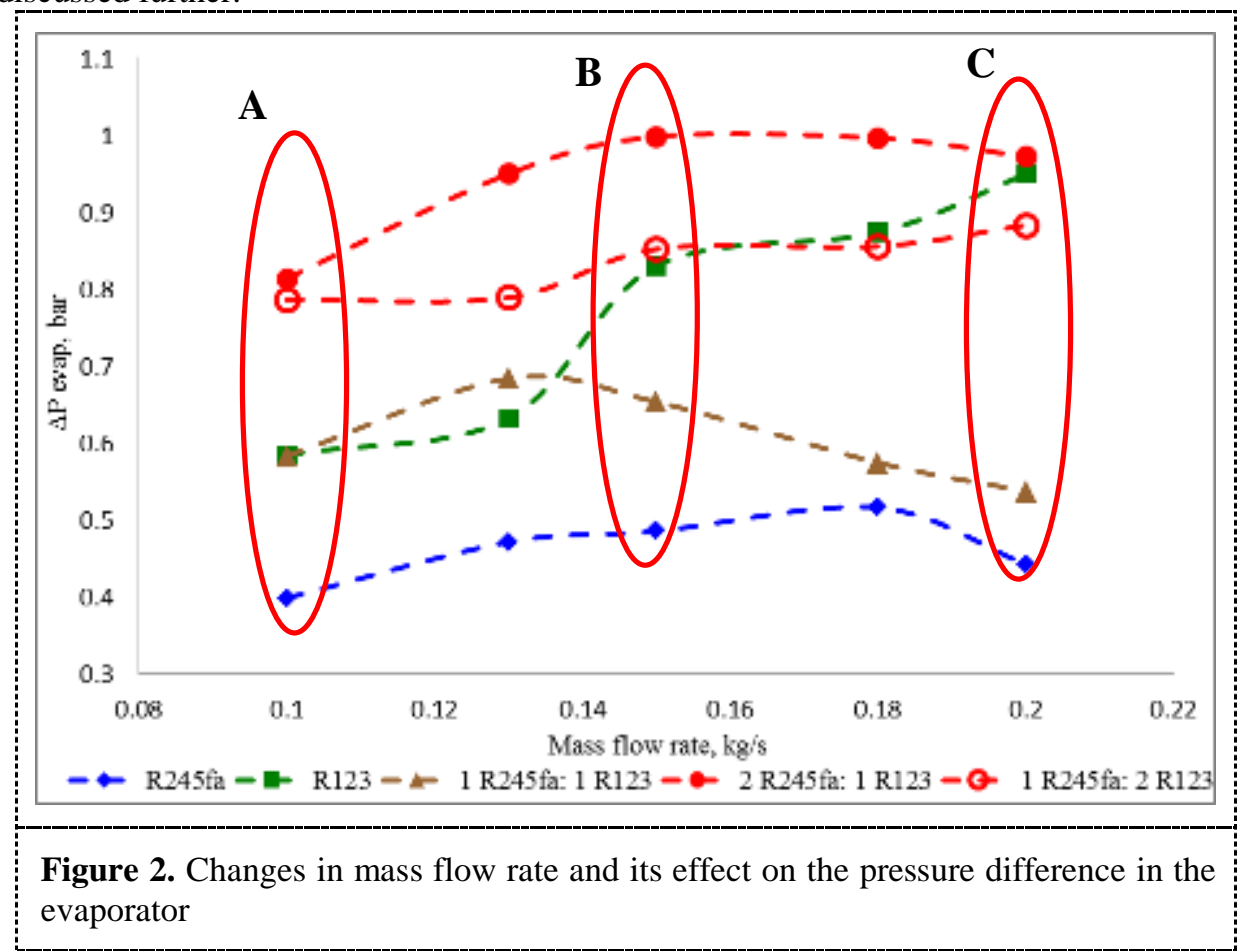

ORC system experiments with changes in mass flow rate have almost the same effect on the behavior of working fluids while in the evaporator area because it looks like a steady trend of pressure difference graph that forms a gentle slope. The working fluid of R245fa has the lowest graphical form, i.e., pressure difference between 0.398 bar and 0,516 bar at all mass flow rate value, followed by mixed R245fa 1:1 R123 working fluid having pressure difference between 0.537 bar and 0.683 bar, then working fluid mixture R245fa 1:2 R123 has a pressure difference of 0.786 bar to 0.882 bar and a working fluid mixture of R245fa 2:1 R123 has a pressure difference of 0.813 bar to 0.998 bar. However, as clearly shown in figure 2, the working fluid of R123 has a different graph of pressure difference when compared with four other working fluid pressure difference charts. The pressure difference of the working fluid R123 gradually trends the graph of a pressure difference of 0.584 bar in a mass flow rate of $0.1 \mathrm{~kg} / \mathrm{s}$ to a pressure rate of 0.949 bar at a mass flow rate of $0.2 \mathrm{~kg} / \mathrm{s}$. Overall, it can be seen that there has been a change in pressure difference in the evaporator area between 0.398 bar to 0.998 bar.
The effect of mass flow rate varies and tends to flat against the pressure difference of each working fluid in the evaporator because of the low-pressure difference was seen in figure 2. The evaporator receives incoming pressure from the pump work, then fluid pass through by obtaining heat energy from the heat source stream. In the evaporator area, there has been significant temperature change, starting from evaporator inlet temperature (T2), saturated liquid temperature (T2 satl), temperature saturated gas (T3 satg) and temperature outlet (T3). In the attachment table, the phase change data from the liquid phase as it exits the pump or goes into the evaporator, the phase change becomes 2 phases in the evaporator and out the evaporator under vapor phase or superheat phase conditions. The data obtained by the pressure difference between the evaporator inlet and the evaporator outlet is so small that it can be ignored. 


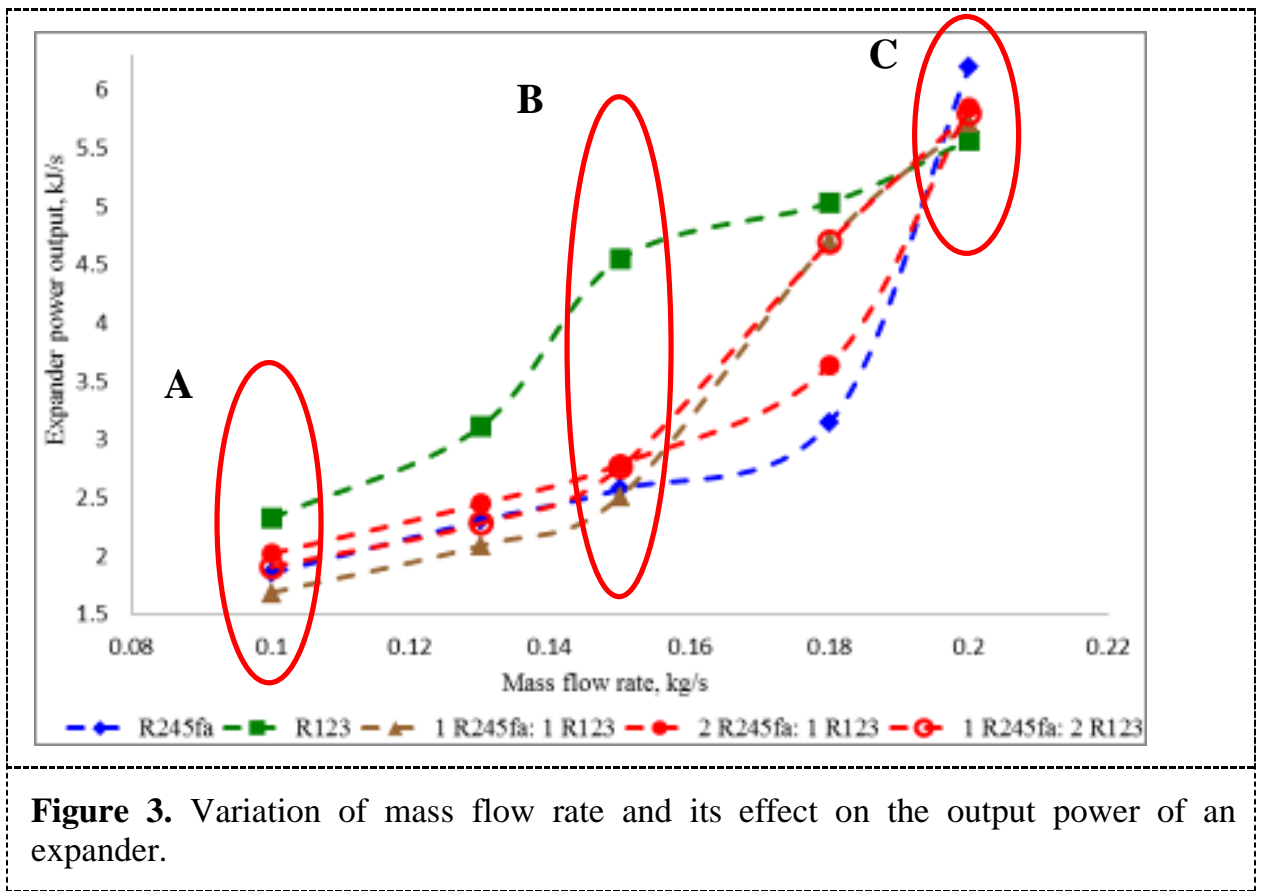

Figure 3 reveals that all working fluid behavior used for experiments has a consistent trend in which the output power of the expander increases sharply against the mass flow rate. At a mass flow rate of 0.1 $\mathrm{kg} / \mathrm{s}$, the working fluid of R123 has the highest output power of $2.32 \mathrm{~kJ} / \mathrm{s}$ when compared to other working fluids. While the working fluid R245fa 2:1 R123 and working fluid R245fa 1:2 R123 has relatively close expander power output of $2,022 \mathrm{~kJ} / \mathrm{s}$ and $1,907 \mathrm{~kJ} / \mathrm{s}$. The working fluid of R245fa 1:1 R123 has the lowest expander power output value of $1.68 \mathrm{~kJ} / \mathrm{s}$ and on the working fluid R245fa of $1.856 \mathrm{~kJ} / \mathrm{s}$. Working fluid
R123 showed a sharp difference and increased with expander power output of $4.55 \mathrm{~kJ} / \mathrm{s}$. Other working fluid, the form of graphic an expander power output showed a sloping with the lowest position working fluid is R245fa and the mixture working fluid are relative between working fluid $\mathrm{R} 245 \mathrm{fa}$ with $\mathrm{R} 123$. At the end of operation ORC system with mass flow rate, $0,2 \mathrm{~kg} / \mathrm{s}$ produces a close output expander power as if one value and visible working fluid R245fa have the highest output power value of $6,197 \mathrm{~kJ} / \mathrm{s}$.

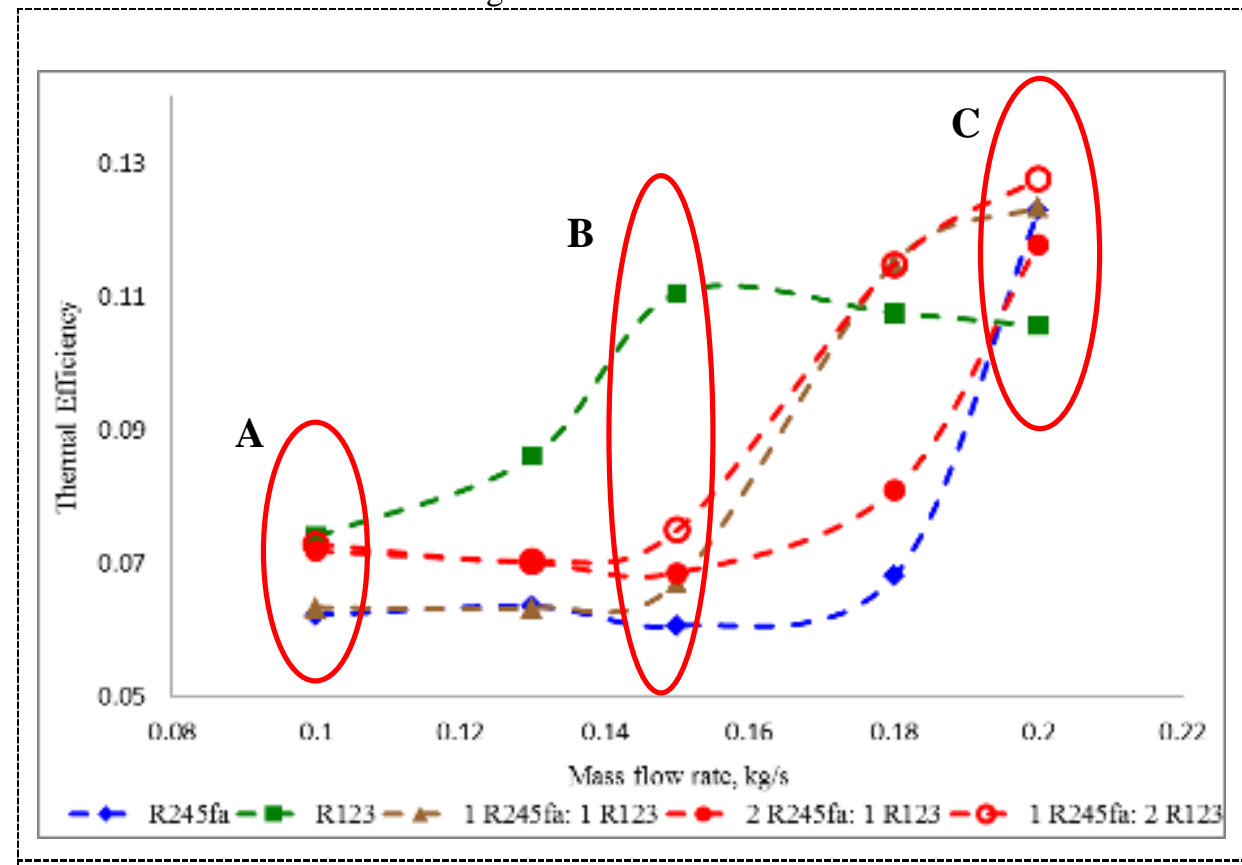

Figure 4. Variation mass flow rate and their effect on thermal efficiency

Thermal efficiency is an overview of the overall performance machine that is operated in the 
laboratory. In the experiment as seen in figure 4 revealed that with a mass flow rate of $0.1 \mathrm{~kg} / \mathrm{s}$, working fluid R123 yields the most significant thermal efficiency of 0.0738 and the lowest is working fluid R245fa with the thermal efficiency of 0.062 . The working fluid mixture produces thermal efficiency with a value that is between the two working fluids R245fa and R123. The overall working fluid used produces increased thermal efficiency as the mass flow rate increases.

Working fluid R123 has the highest rate of thermal efficiency increase compared to the other working fluid, which yields thermal efficiency of 0.11 , but with the addition of mass flow rate in the experiments that have been done resulting in sloping thermal efficiency and making the working fluid R123 thermal efficiency is lowest.

In contrast to working fluid R245fa, at the beginning of the experiment yielded mostly gentle thermal efficiency when compared with other working fluids, after operating at a mass flow rate of $0.18 \mathrm{~kg} / \mathrm{s}$, thermal efficiency increased significantly.

\subsection{Explanations circle $A, B$ and $C$ in figure 2 , figure 3, and figure 4}

Figure 2, figure 3 and figure 4 reveals the effect of mass flow rate changes on the pressure difference in the evaporator, expander power output, and thermal efficiency by reading manually or digitally installed size parameters but cannot read properties that occur under those conditions. As researchers have known the properties that occur during the experimental conditions are crucial to know more deeply what happens in working fluid and the cause of mechanical phenomena that occur as a result of changes in properties.

Each working fluid applied to the existing machine in the laboratory has different properties so that when the experiment with the mass flow rate of $0,1 \mathrm{~kg} / \mathrm{s}$ get the value pressure difference in the evaporator, expander power output and thermal efficiency are different. At that point (as already circled in red and marked with the letter A) when depicted in Ts diagram will get the picture as in figure 5 .

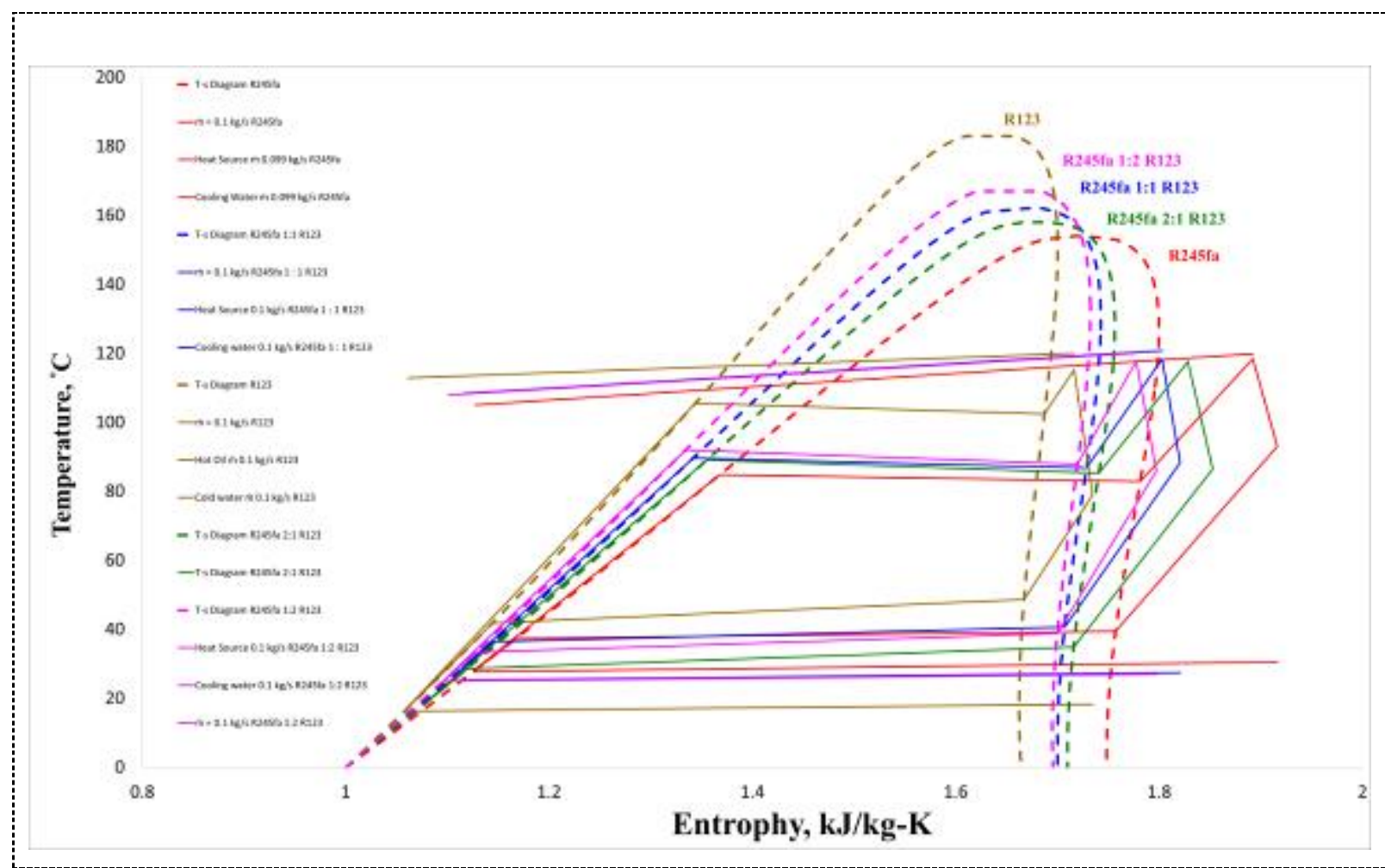

Figure 5. Ts diagram R245fa, R123 and their mix when positioning in red circle with initials letter A in figure. 2,3 and 4 .

In figure 5, there is a very noticeable difference between the height of the dome of each working fluid, where the lowest is working fluid R245fa, followed by working fluid mix of R245fa 2:1 R123, R245fa 1:1 
R123, R245fa 1:2 R123 and the last pure working fluid R123. This description is clear because it describes the Ts diagram required temperature value (T) as critical intensive properties that the value of freezing point, boiling point, critical temperature and properties working fluid differ for each working fluid as can be seen in table 2. As for Entropy (s) is an extensive property that will vary as the ORC temperature

changes

Table 3. Physical and Thermodynamic Properties of R245fa and R123

\begin{tabular}{lll}
\hline Property & R245fa & R 123 \\
\hline Molecular weight & $134 \mathrm{~kg} / \mathrm{kmol}$ & $152,9 \mathrm{~kg} / \mathrm{kmol}$ \\
Boiling point & $15,3{ }^{\circ} \mathrm{C}$ & $27,9{ }^{\circ} \mathrm{C}$ \\
Freezing point & $<-107{ }^{0} \mathrm{C}$ & $-107{ }^{0} \mathrm{C}$ \\
Critical Temperature & $154,05{ }^{\circ} \mathrm{C}$ & $183,6{ }^{0} \mathrm{C}$ \\
Critical Pressure & $36,4 \mathrm{bar}$ & $36,57 \mathrm{bar}$ \\
Vapor Viscosity & $10,3 \mathrm{cP}$ & $0,011 \mathrm{cP}$ \\
Liquid Viscosity & $402,7 \mathrm{cP}$ & $0.456 \mathrm{cP}$ \\
Vapor Specific Heat & $0,89 \mathrm{~kJ} / \mathrm{kg}^{0} \mathrm{~K}$ & $0,72{ }^{\circ} \mathrm{kJ} / \mathrm{kg}^{0} \mathrm{~K}$ \\
Liquid Specific Heat & $1,36 \mathrm{~kJ} / \mathrm{kg}$ & $0,965 \mathrm{~kJ} / \mathrm{kg}^{0} \mathrm{~K}$ \\
Liquid Thermal Conductivity & $0,081 \mathrm{~W} / \mathrm{m}^{0} \mathrm{~K}$ & $0,096 \mathrm{~W} / \mathrm{m}^{0} \mathrm{~K}$ \\
\hline
\end{tabular}

Pressure difference ( $\triangle$ Pevap) in figure. 2 is obtained from the difference of pressure at evaporator input (P2) and outlet (P3), while there is a difference between working fluid when seen in figure 5 shows the difference of Ts diagram constructed from the difference of boiling point, freezing point, critical temperature and critical pressure as shown in Table 2. Although using the same mass flow rate of $0.1 \mathrm{~kg} / \mathrm{s}$ (circle A), pump performance produces volume rate and shows different pressure $\mathrm{P} 2$ as resulting from different molecular weight working fluids. For working fluid R245fa has the P2 value equal to 8,89 bar, so $\mathrm{P} 2$ saturated liquid ( $\mathrm{P} 2$ satl) is assumed as 8,89 bar, after exiting from evaporator value of pressure P3 equal to 8,49 bar then $\mathrm{P} 3$ saturated gas (P3satg) is assumed 8,49 bar. Thus working fluid R245fa when operating inside the evaporator has a pressure different ( $\triangle$ Pevap) of 0,4 bar. This case also happens for another working fluid R245fa 1:1 R123 pressure P2 of 8.99 bar, assumed P2satl 8.99 bar, pressure P3 of 8.41 bar so assumed P3satg equal to 8.99 and yield $\triangle$ Pevap of 0,58 bar. Then for working fluid R123 yields $\mathrm{P} 2=8,88$ bar, $\mathrm{P} 2$ satl $=8.88$ bar, $\mathrm{P} 3=8.3$ bar, $\mathrm{P} 3$ satg $=8.3$ bar and $\Delta$ Pevap $=0.58$ bar. Working fluid mixture R245fa 1:2 R123 yields P2 $=8.78$ bar, $\mathrm{P} 2$ satl $=8.78$ bar, $\mathrm{P} 3=7.99$ bar, $\mathrm{P} 3 \mathrm{satg}=7.99$ bar and
$\Delta$ Pevap $=0.786$ bar. While working fluid of R245fa 2:1 R123 mixture yielded P2 = 9,37 bar, P2satl = 9,37 bar, P3 $=8,55$ bar, P3satg $=8,55$ bar and $\Delta$ Pevap $=$ 0,813 bar.

In figure. 2 for circle $\mathrm{B}$ and $\mathrm{C}$, the condition of the properties values can be seen in the attachment, when compared to the overall trend that appears is random. R245fa and R245fa 1:1 R123 mixture dome slope, R245fa 2:1 R123 mixture and R245fa 1:2 R123 resulting in a relatively high overall $\triangle$ Pevap but also randomly trendy, especially for R123 which is seen to be more progressive as $\Delta$ Pevap increases with increasing mass flow rate. Working fluid R123 in circle A produces $\triangle$ Pevap of 0.58 bar, in circle $\mathrm{B}$ produces $\triangle$ Pevap of 0.83 bar and in a circle, $\mathrm{C}$ produces $\triangle$ Pevap of 0.95 bar. This case is because working fluid R123 has the most considerable molecular weight and liquid thermal conductivity higher than working fluid others. The molecular weight of R123 is $152.9 \mathrm{~kg} / \mathrm{kmol}$, while for R245fa has a molecular weight of $134 \mathrm{~kg} / \mathrm{kmol}$, then the molecular weight was working fluid of R245fa and R123 mixtures are among them. The liquid thermal conductivity of R123 was $0.96 \mathrm{~W} / \mathrm{m} 0 \mathrm{~K}$ while for $\mathrm{R} 245 \mathrm{fa}$ of $0.081 \mathrm{~W} / \mathrm{m} 0 \mathrm{~K}$. 
In figure 3 reveals the change of mass flow rate to expander power output, where the expander power output is obtained from multiplying mass flow rate by the difference of enthalpy expander inlet (h3) with enthalpy expander outlet (h4). Because mass flow rate is the central mathematical component to get expander power output value so mass flow rate will influence significantly to expander output change. In the circle, A fig. 3, working fluid R123 has the highest expander power output price compared to the other working fluid of $2.33 \mathrm{~kJ} / \mathrm{s}$ with the h3 composition of 452,27 $\mathrm{kJ} / \mathrm{kg}$ and $\mathrm{h} 4$ of $433,45 \mathrm{~kJ} / \mathrm{kg}$. Whereas for the other working fluid are below the respective working fluid of R245fa 2:1 R123 mixture having $h 3$ equal to $484,32 \mathrm{~kJ} / \mathrm{kg}$, h4 equal to $463,91 \mathrm{~kJ} / \mathrm{kg}$ and expander power output $2,022 \mathrm{~kJ} / \mathrm{s}$. Furthermore, the successive working fluid of R245fa 1:2 R123 mixture has a h3 of $468.55 \mathrm{~kJ} / \mathrm{kg}$, h4 of $449.37 \mathrm{~kJ} / \mathrm{kg}$ and expander power output $1.9 \mathrm{~kJ} / \mathrm{s}$, working fluid R245fa has h3 of 505, $08 \mathrm{~kJ} / \mathrm{kg}$, h4 equal to $487,20 \mathrm{~kJ} / \mathrm{kg}$ and expander power output $1,856 \mathrm{~kJ} / \mathrm{s}$, working fluid mixture R245fa 1:1 R123 has h3 of 476,56 kJ/kg, h4 of 457,65 $\mathrm{kJ} / \mathrm{kg}$ and expander power output $1.68 \mathrm{~kJ} / \mathrm{s}$. Working fluid R123 has the highest enthalpy different at 18.82 $\mathrm{kJ} / \mathrm{kg}$ when compared with other working fluids, because the working fluid R123 has the most significant molecule weight $152.9 \mathrm{~kg} / \mathrm{kmol}$ so that when an expansion process in the expander molecule weight provides a more massive motion energy intake so that the difference between $\mathrm{h} 3$ and $\mathrm{h} 4$ is also more significant, if multiplied with mass flow rate will be obtained expander power output is more significant as well.

In figure 3 circle $B$ undergoes the same process, and experimental results show that general working fluid R123 has the most massive expander power output and the lowest is R245fa. This difference is related to the difference of molecular weight between R123 of $152.9 \mathrm{~kg} / \mathrm{kmol}$ with R245fa of $134 \mathrm{~kg} / \mathrm{kmol}$ which gives an effect of the difference of energy intake by expander at expansion process. The working fluid of R245fa mixture with R123 has a relative value between them to produce expander output is also among them.

In figure 3 circle $\mathrm{C}$ there is a change of position, primarily working fluid R245fa and R123 as if the displacement of the place, where working fluid R245fa produce higher output expander of $6,2 \mathrm{~kJ} / \mathrm{s}$, while working fluid R123 equal to $5,57 \mathrm{~kJ} / \mathrm{s}$, for working fluid mixture is relative between the two pure working fluids. Experiments on circle $\mathrm{C}$ have a mass flow rate of $0.2 \mathrm{~kg} / \mathrm{s}$, so the fluid velocity and volume rate flow increases. Although the mass flow rate is almost the same, the working fluid of R245fa is higher than the other working fluids. This case corresponds to a larger enthalpy R245fa of h3 $476.42 \mathrm{~kJ} / \mathrm{kg}$, h4 of $457.95 \mathrm{~kJ} / \mathrm{kg}$ yielding a difference of $13.47 \mathrm{~kJ} / \mathrm{kg}$.
Thermal efficiency as a representation of ORC system efficiency measures the level of input energy provided to the working fluid through the evaporator and converted into the network output produced by the expander. When comparing figure 3 about expander power output with figure 4 on thermal efficiency provide an almost similar picture of a trend that increases along with the increase in mass flow rate. ORC system efficiency which has the highest thermal efficiency in fig. 4 circle A with a mass flow rate of $0.1 \mathrm{~kg} / \mathrm{s}$ occurs when using a working fluid R123 of 0.074 with the rate of work per unit mass of vapor passing through the expander $\left(W_{t} / m^{*}\right)$ of $h 3$ of 452.27 $\mathrm{kJ} / \mathrm{kg}$ minus $\mathrm{h} 4$ of $433,45 \mathrm{~kJ} / \mathrm{kg}$, the rate of power input per unit of mass passing through the pump $\left(W_{p} / m\right)$ of h2 of $217.91 \mathrm{~kJ} / \mathrm{kg}$ minus $\mathrm{h} 1$ of 216.48 $\mathrm{kJ} / \mathrm{kg}$. Both of work is $\left(W_{\mathrm{t}} / m^{\circ}\right)$ minus $\left(W_{\mathrm{p}} / m\right)$ is divided by the rate of heat transfer from the energy source to the working fluid per unit of mass passing through the evaporator $\left(\phi_{\mathrm{in}} / \mathrm{m}\right)$ of h3 of $452.27 \mathrm{~kJ} / \mathrm{kg}$ minus h2 of $433.45 \mathrm{~kJ} / \mathrm{kg}$, followed by a mixture working fluid of R245fa 1:2 R123 with thermal efficiency of 0.073 with $W_{t} / m$ condition of $\mathrm{h} 3$ of 468 , $55 \mathrm{~kJ} / \mathrm{kg}$ minus h4 of $449.37 \mathrm{~kJ} / \mathrm{kg}, W_{\mathrm{p}} / m$ of $\mathrm{h} 2$ of $229.52 \mathrm{~kJ} / \mathrm{kg}$ minus $\mathrm{h} 1$ of $227.81 \mathrm{~kJ} / \mathrm{kg}$, while $\phi_{\mathrm{in}} / \mathrm{m}^{\mathrm{m}}$ of h3 is $468,55 \mathrm{~kJ} / \mathrm{kg}$ minus h2 equal to $229,52 \mathrm{~kJ} / \mathrm{kg}$. Further a mixture working fluid of R245fa 2:1 R123 with thermal efficiency equal to 0,072 and condition of $W_{\mathrm{t}} / \dot{m}$ from h3 equal to $484,32 \mathrm{~kJ} / \mathrm{kg}$ minus $\mathrm{h} 4$ equal to $463,91 \mathrm{~kJ} / \mathrm{kg}, W_{p} / \mathrm{m}$ from h2 equal to 224,9 $\mathrm{kJ} / \mathrm{kg}$ minus h1 of $223.2 \mathrm{~kJ} / \mathrm{kg}$, while $\phi_{\mathrm{in}} / \mathrm{m}^{\mathrm{n}}$ of $\mathrm{h} 3$ is $484,32 \mathrm{~kJ} / \mathrm{kg}$ minus $\mathrm{h} 2$ of $224,9 \mathrm{~kJ} / \mathrm{kg}$, a mixture working fluid of R245fa 1:1 R123 with thermal efficiency equal to 0,063 with condition $W_{\mathrm{t}} / \mathrm{m}$ from $\mathrm{h} 3$ equal to $476,56 \mathrm{~kJ} / \mathrm{kg}$ minus h4 of $457.65 \mathrm{~kJ} / \mathrm{kg}$, $W_{p} / \tilde{m}$ of $\mathrm{h} 2$ of $233.92 \mathrm{~kJ} / \mathrm{kg}$ minus $\mathrm{h} 1$ of 232.81 $\mathrm{kJ} / \mathrm{kg}$, while $\phi_{\mathrm{in}} / \mathrm{m}_{\mathrm{m}}$ of h3 is $476,56 \mathrm{~kJ} / \mathrm{kg}$ minus $\mathrm{h} 2$ of $233,92 \mathrm{~kJ} / \mathrm{kg}$, and last working fluid R245fa with thermal efficiency equal to 0,062 with condition $W_{\mathrm{t}} / \mathrm{m}$ from $\mathrm{h} 3$ equal to $505,08 \mathrm{~kJ} / \mathrm{kg}$ minus $\mathrm{h} 4$ of $487.20 \mathrm{~kJ} / \mathrm{kg}, W_{p} / m$ of $\mathrm{h} 2$ of $233.92 \mathrm{~kJ} / \mathrm{kg}$ minus $\mathrm{h} 1$ of $232.81 \mathrm{~kJ} / \mathrm{kg}$, while $\phi_{\mathrm{in}} / \mathrm{m}$ of $\mathrm{h} 3$ is $476,56 \mathrm{~kJ} / \mathrm{kg}$ minus $\mathrm{h} 2$ of $233,92 \mathrm{~kJ} / \mathrm{kg}$.

In figure 4 circle B working fluid R123 has the greatest thermal efficiency 0.11 with condition $W_{t} / m$ from $\mathrm{h} 3$ equal to $444,84 \mathrm{~kJ} / \mathrm{kg}$ less $\mathrm{h} 4$ equal to 418,55 $\mathrm{kJ} / \mathrm{kg}, W_{\mathrm{p}} / \mathrm{m}$ from h2 equal to $217,52 \mathrm{~kJ} / \mathrm{kg}$ minus $\mathrm{h} 1$ of $216.40 \mathrm{~kJ} / \mathrm{kg}$, while $\phi_{\mathrm{in}} / \mathrm{m}$ of h3 is $444,84 \mathrm{~kJ} / \mathrm{kg}$ minus h2 equal to $217,52 \mathrm{~kJ} / \mathrm{kg}$, whereas the lowest is R245fa with thermal efficiency equal to 0,061 with condition $W_{t} / \dot{m}$ from $\mathrm{h} 3$ equal to $496,03 \mathrm{~kJ} / \mathrm{kg}$ minus h4 of $479.49 \mathrm{~kJ} / \mathrm{kg}, W_{\mathrm{p}} / \mathrm{m}$ of h2 of $240.63 \mathrm{~kJ} / \mathrm{kg}$ minus h1 of $239.59 \mathrm{~kJ} / \mathrm{kg}$, while $\phi_{\mathrm{in}} / \dot{m}$ of $\mathrm{h} 3$ is $496.03 \mathrm{~kJ} / \mathrm{kg}$ minus h2 of $240.63 \mathrm{~kJ} / \mathrm{kg}$. Next comes fig. 4 circle $\mathrm{C}$ changed with working fluid R123 resulted in the lowest thermal efficiency of 0.105 with 
$W_{\mathrm{t}} / \mathrm{m}$ condition of $\mathrm{h} 3$ of $496.03 \mathrm{~kJ} / \mathrm{kg}$ minus $\mathrm{h} 4$ of $479.49 \mathrm{~kJ} / \mathrm{kg}, W_{p} / \dot{m}$ of $\mathrm{h} 2$ of $240,63 \mathrm{~kJ} / \mathrm{kg}$ minus h1 of $239.59 \mathrm{~kJ} / \mathrm{kg}$, while $\phi_{\text {in }} / \mathrm{m}$ of h3 is $496.03 \mathrm{~kJ} / \mathrm{kg}$ minus h2 of $240.63 \mathrm{~kJ} / \mathrm{kg}$.

\section{CONCLUSION}

In this paper, a comprehensive study on the pressure difference effect at evaporator to ORC system has been investigated. In the exploration of the pressure difference, the quantitative relationship between the mass flow rate and the system performance was innovatively studied. The following conclusions can be drawn:

1. The difference of boiling point, freezing point, critical temperature and critical pressure could be identified by Ts diagram with the lowest dome of R245fa followed by working fluid mix of R245fa 2:1 R123, R245fa 1:1 R123, R245fa 1:2 R123 and the last pure working fluid R123. This is caused by different molecular weight with the lowest of R245fa and the highest of R123.

2. Pump performance produces volume rate and shows pressure different at evaporator with R245fa 2:1 R123 mixture and R245fa 1:2 R123 resulting in a relatively high overall $\triangle$ Pevap.

3. Working fluid R123 was in circle A produces $\Delta$ Pevap of 0.58 bar, in circle B with $\triangle$ Pevap of 0.83 bar and in a circle, $C$ with $\Delta$ Pevap of 0.95 bar, because working fluid R123 has the most considerable molecular weight and liquid thermal conductivity higher than other working fluid.

4. When an expansion process in the expander, molecule weight provides a more massive motion energy intake, therefore working fluid R123 has the highest expander power output and the greatest thermal efficiency.

\section{REFERENCES}

[1] Song J Li $\quad$ Y $\quad$ Gu $\quad$ GW Zhang L 2014 Thermodynamic analysis and performance optimization of an ORC (Organic Rankine Cycle) system for multi-strand waste heat sources in petroleum refining industry Energy 71 (15) 673-680.

[2] Sun WQ Yue XY Wang YH 2017 Exergy efficiency analysis of ORC (Organic Rankine Cycle) and ORC-based combined cycles driven by low-temperature waste heat Energy Convers Manag 135 (1) 63-73.

[3] Cao Y Dai YP 2017 Comparative analysis on off-design performance of a gas turbine and ORC combined cycle under different operation approaches Energy Conversion Management 135 (1) 84-100.

[4] Surindra MD 2019 Eksperimental Studi Performance Organic Rankine Cycle (ORC) Menggunakan Fluida Kerja R245fa Dengan Sumber Panas di Evaporator $120^{\circ} \mathrm{C}$ Rekayasa 143.

[5] Guo Q Li M Tian X 2020 Experimental study on flow boiling heat transfer characteristics of R134a, R245fa and R134a/R245fa mixture at high saturation temperatures International Journal of Thermal Sciences 150106195.

[6] Galloni, G. Fontana, S. Staccone, 2015 Design and experimental analysis of a mini ORC (organic Rankine cycle) power plant based on R245fa working fluid, Energy 90 768-775.

[7] Prasetyo T Surindra MD Caesarendra W Taufik Glowacz A Irfan M Glowacz W 2020 Influence of Superheated Vapour in Organic Rankine Cycles with Working Fluid R123 Utilizing Low-Temperature Geothermal Resources Symmetry 121463.

[8] Sarmiento ALE, Camacho RGR Oliveira W 2020 Performance analysis of radial-inflow turbine of ORC: New combined approach of preliminary design and 3D CFD study Journal of Mechanical Science and Technology 34 (6).

[9] Surindra MD Prasetyo T Caesarendra W Mahlia TMI Taufik 2019 Comparison of the Utilization of $110{ }^{\circ} \mathrm{C}$ and $120{ }^{\circ} \mathrm{C}$ Heat Sources in a Geothermal Energy System Using Organic Rankine Cycle (ORC) with R245fa, R123, and Mixed-Ratio Fluids as Working Fluids Processes 7113.

[10] Kong R Deethayat T Asanakham AVorayos N Kiatsiriroat T 2019 Thermodynamic performance analysis of a R245fa organic Rankine cycle (ORC) with different kinds of heat sources at evaporator Case Studies in Thermal Engineering 13100385. 